\title{
Recent Advances in Detonation Techniques for High-Enthalpy Facilities
}

\author{
Frank K. Lu, ${ }^{*}$ Donald R. Wilson, ${ }^{\dagger}$ W. Scott Stuessy ${ }^{\ddagger}$ \\ University of Texas at Arlington, Arlington, Texas 76019 \\ Robert J. Bakos, ${ }^{\S}$ and John I. Erdos $\$$ \\ GASL, Ronkonkoma, New York 11779
}

\begin{abstract}
Detonations can be used to generate a high-pressure gas of high acoustic speed to drive a shock tube. Recently, detonation-driven facilities have been implemented for meaningful hypervelocity testing. These facilities can be operated with the detonation wave propagating downstream or upstream. The advantages and problems associated with these methods are discussed. In addition to a performance comparison between these two modes, comparisons with other high-performance techniques, such as free-piston and gun tunnels, is also made. At present, detonation-driven facllitles are generally of lower performance than free-piston tunnels. However, they appear easier to operate.
\end{abstract}

\section{Nomenclature}

\begin{tabular}{|c|c|}
\hline$a$ & $=$ acoustic speed \\
\hline M & $=$ Mach number \\
\hline$p$ & $=$ pressure \\
\hline$P_{i, j}$ & $=p_{i} / p_{j}$, pressure ratio \\
\hline$P_{i, j}^{\prime}$ & $=p_{i} / p_{j}-1$ \\
\hline$u$ & $=$ velocity \\
\hline$T$ & $=$ temperature \\
\hline$\gamma$ & $=$ specific heat ratio \\
\hline
\end{tabular}

shock tube principles. Consequently, these facilities have short test times, typically in the $0.1-10 \mathrm{~ms}$ range. This short test time contrasts drastically from those achievable using continuous or blowdown (that is, "conventional") facilities. ${ }^{1}$ Despite this limitation, short duration facilities appear to be the primary means for achieving hypervelocity flows at present. The underlying principle is to store energy over a long period of time, lessening the input power requirement, and then releasing the accumulated energy rapidly. The tradeoff between flow duration and flow enthalpy is clearly manifested.

The alternative to impulse facilities may be extremely prohibitive in cost, especially if large conventional tunnels are contemplated. Additionally, one may even argue that for certain purposes, there is no other really viable alternative, such as in simulating orbital flight or flight through planetary atmospheres. ${ }^{2}$ The latter application exploits the fact that impulse facilities can use test gases other than air. Moreover, elaborate thermal protection of the test model or of the instrumentation can be dispensed with because of the short time of passage of the heated test gas. Heat-transfer studies with appropriate cold-wall boundary conditions encountered in flight can be performed using short duration facilities. Other than aerothermodynamic applications, impulse facilities can be used for instrumentation and facility development.

The most serious limitation of short duration facilities is the test time. This difficulty has, fortunately, been greatly reduced with modern, high speed, data acquisition systems and innovative techniques. Nevertheless, a proper appreciation of the limitations of short duration facilities is necessary to enable its advantages to be effectively exploited.

Present interest in high-enthalpy facilities stems from the need to test advanced air-breathing hypersonic propulsion systems. ${ }^{3}$ In particular, the facility should be capable of providing post bow shock conditions 
for testing concepts such as oblique detonation wave propulsion. ${ }^{4}$ Recent proposals for achieving high stream enthalpies considered radiative energy addition to a supersonic flow ${ }^{5}$ or the incorporation of a magnetohydrodynamic accelerator. ${ }^{6}$ Although proposed for continuous or blowdown operation, the feasibility of these facility advances can be studied using shock tubes.

In view of the enthalpy requirements for hypervelocity testing, the shock tube must incorporate a high performance driver. Warren and Harris ${ }^{7}$ classified high performance drivers as (a) conventional drivers using high pressure and high acoustic speed gases, $(b)$ electric and magnetic field interaction drivers, $(c)$ detonation, that is, explosive drivers, and $(d)$ those that derive their flow characteristics from the coupling of energy addition and wave processes in an unconventional manner. Examples of conventional drivers, which are well developed, include electrical energy discharge, internal or external heating of hydrogen or helium driver gas, and piston compression. The last technique is found in free piston $^{8}$ and gun tunnels. ${ }^{9}$ Electric and magnetic field interaction drivers, and detonation drivers appear to be less well developed. The final class of techniques includes the expansion tube ${ }^{2}$ and the use of shock waves or detonation waves to achieve a high pressure, hot driver gas. ${ }^{10}$

Although Warren and Harris listed many high performance techniques, only a few of these appear feasible. The free piston technique appears to be the most developed and have been implemented in different institutions, including the largest such facility at Göttingen, Germany. ${ }^{11}$ The free piston technique is generally thought to be capable of achieving extremely high enthalpies. However, there is recent interest in using detonation techniques to achieve high enthalpies, albeit somewhat lower than that achievable by free piston techniques. Nevertheless, detonation techniques possess favorable features to ensure that they occupy a useful niche in hypervelocity testing. They are the subject of this review. To understand the use of detonation drivers, a brief summary of shock tube principles will be given next.

\section{Background}

Shock Tube Principles

A shock tube, shown schematically in Fig. 1a, consists essentially of a high pressure, driver section separated from the low pressure, driven section by a diaphragm. Gases fill both sections. When the diaphragm is ruptured, the high pressure gas, at an initial state 4 , expands into the low pressure section, filled with gas at an initial state 1. Propagating into the driven gas ahead of this expansion is a shock wave. This shock compresses the driven gas, thereby changing its state from 1 to 2 . This slug of shock processed, driven gas-between the propagating shock and the arrival of the contact surface

\section{Diaphragm}

(4) Driver tube: Driven tube is

\begin{tabular}{c:c|c|}
\hline & 3 & \\
\hline $\begin{array}{c}\text { Expansion } \\
\text { wave }\end{array}$ & Contact Primary \\
\hline surface shock
\end{tabular}

a. Schematic.

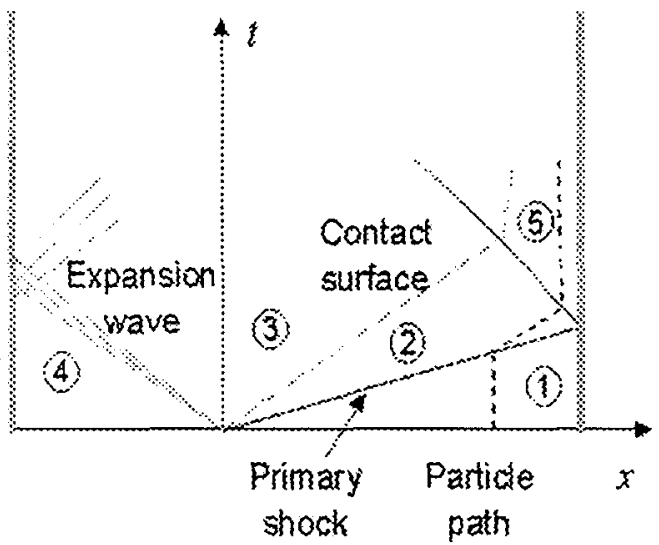

b. Wave diagram.

Figure 1: Ideal wave processes in a shock tube.

between the driver and driven gas-forms the test gas. (The test gas can be further processed; for example, it can be accelerated by a nozzle, as in a shock tunnel.) By using different driver gases or by having the driver and driven gases at different initial pressures and temperatures, the shocked state of the driven gas can be preset. Quasi one-dimensional theory yields the following implicit expression for the pressure ratio of the test gas after shock passage as

$$
P_{4,1}=P_{2,1}\left\{1-\frac{\left(\gamma_{4}-1\right)\left(a_{1} / a_{4}\right)\left(P_{2,1}^{\prime}\right)}{\sqrt{2 \gamma_{1}\left[2 \gamma_{1}+\left(\gamma_{1}+1\right) P_{2,1}^{\prime}\right]}}\right\}^{-2 \gamma_{4} /\left(\gamma_{4}-1\right)}
$$

The key parameter governing shock tube performance is the shock Mach number $M_{s}$, defined as the shock speed referred to the initial speed of sound in the driven gas. The shock Mach number is given by

$$
M_{s}=\sqrt{1+\frac{\gamma_{1}+1}{2 \gamma_{1}} P_{2,1}^{\prime}}
$$

Although actual shock tube processes are complicated by non-ideal behavior, such as boundary layer growth and finite diaphragm opening times, the technique has been sufficiently developed for shock tube performance to be well understood. Shock tubes are used in many scientific disciplines and these tubes have been built in a broad range of sizes, with a bewildering number of enhancements. 
The theoretical performance of a shock tube is displayed in Fig. 2, where helium is the driver gas and air is the driven gas. Both gases are assumed perfect because real gas effects in the test gas up to a shock Mach number of 8 are not large. In the figure, the initial driver-to-driven pressure ratio $p_{4} / p_{1}$ is plotted as a function of $M_{s}$ for different values of $a_{4} / a_{1}$. Also plotted as a dotted line is the pressure ratio across the propagating shock $p_{2} / p_{1}$.

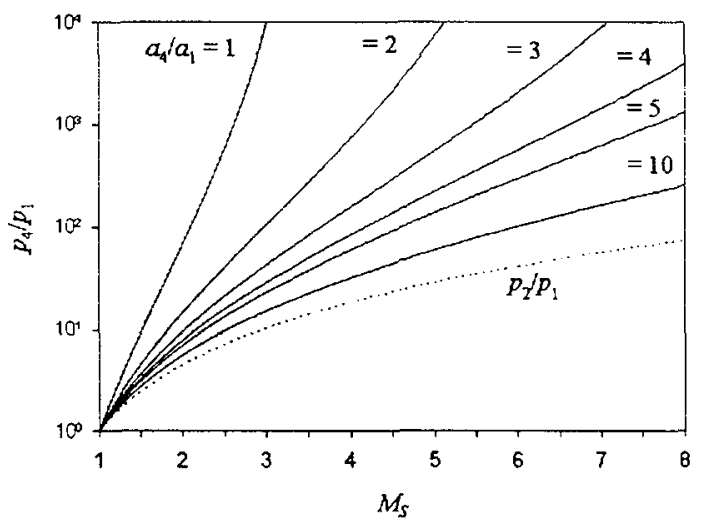

Figure 2: The effect of acoustic speed and initial driver pressure ratio (helium driver gas and the air test gas).

Figure 2 shows that a cold driver, with a low sonic speed, achieves a practical shock Mach number of only about 3. This limited shock Mach number led to schemes to improve driver performance in order to provide adequate hypervelocity, real gas simulation. The figure shows that to achieve large shock Mach numbers without incurring an exorbitant initial pressure ratio, the sonic speed of the driver gas must be raised. In other words, the driver gas must be of low molecular weight and must be heated. For example, to achieve a shock Mach number of 8 , the theoretical initial pressure ratio needs to be only 1300 and 260 for acoustic speed ratios of 5 and 10 respectively. In practice, using a value of $p_{1}=10 \mathrm{kPa}$ for instance, $M_{s}=8$ can be achieved with a value of $p_{4}$ of only $2.6 \mathrm{MPa}$ for an acoustic speed ratio of 10 . (Such a pressure can be obtained without using highly specialized industrial equipment.) Unfortunately, if the air is at room temperature, the helium must be at a temperature of $3500 \mathrm{~K}$. The only practical means of achieving this high temperature without destroying the facility is to heat the gas in a transient manner.

\section{Detonation Wave Drivers}

In ground test applications, the free piston technique for producing a hot driver gas is well-developed. Nevertheless, detonations can also be used to obtain a hot driver gas with a large acoustic speed. Detonation drivers are an inexpensive, simple, viable alternative to free-piston drivers in obtaining high enthalpies be- cause the technique dispenses with a fast moving, heavy piston. Detonations are also attractive compared to combustion as a transient, heating method. ${ }^{12}$ The low velocity combustion depends on factors such as ignition energy, number of igniters, initial turbulence, flame propagation and size of tube, all of which cause difficulties in reproducibility. ${ }^{13}$

The detonation-driven shock tube was first proposed by $\operatorname{Bird}{ }^{14}$ and was subsequently studied by several investigators. ${ }^{15-17}$ This concept has recently been further developed. ${ }^{10,13,18-29}$ A detonation process is typically established in a driver tube filled with a nearstoichiometric oxyhydrogen mixture, although other gas combinations, such as acetylene and oxygen, ${ }^{17}$ are possible. The mixture pressure can be quite low, thus eliminating the need for thick metal diaphragms. The detonation process produces a low molecular weight driver gas at high temperature and pressure, all of which are desirable features. The sudden pressure rise produced by the detonation causes the primary diaphragm to rupture, thus establishing a shock wave in the driven tube.

\section{Implementation}

At present, detonation driven facilities have been reported by the University of Technology, Aachen, Germany ${ }^{13,23}$ the Institute of Mechanics, Chinese Academy of Sciences, ${ }^{18-22}$ GASL, Ronkonkoma, New York ${ }^{24,25,27}$ and the University of Texas at Arlington. ${ }^{28,29}$ These facilities use an oxyhydrogen mixture as the driver gas, with helium dilution as necessary. Table 1 summarizes the major characteristics of the detonation drivers in the four institutions mentioned, indicating the propagation mode of the detonation wave. The detonation wave can propagate either downstream or upstream. Thus, the mode of propagation can serve as a means of classifying detonation wave drivers.

In the downstream propagation mode, the ignition source is located at the upstream end of the driven tube, producing a detonation wave that propagates downstream. The main wave processes are shown schematically in Fig. 3. The detonation wave, denoted as a solid line, propagates downstream into region 4. Momentum of the burned gas following the detonation wave is also in the downstream direction and produces a stronger shock for a given detonation overpressure. However, the detonation wave is followed by Taylor rarefaction, shown as chained lines in region $4^{\prime}$, which progressively attenuates the strength of the driven shock. The detonation wave propagating into 4 is reflected at the diaphragm, to yield an effective, unsteady condition given by $4^{\prime \prime}$. The reflection of the detonation wave at the diaphragm interface generates a shock which propagates into region 1 , being driven by the high enthalpy detonation products at state $4^{\prime \prime}$. The burned gas then exhausts into the driven section to reach state 3 . This gas is separated by an interface, shown in Fig. 3 as a 
dotted line, from the post-shock driven gas at state 2 . Further wave processes are not shown but may be important, such as in creating a high pressure, stagnant region 5 .

An example of detonation tube pressure traces for the downstream propagation mode is shown in Fig. $4 .{ }^{29}$ The detonation tube was filled with a stoichiometric oxyhydrogen mixture at 6 atm. Transducer (3) was closer to the igniter than transducer (4) and thus recorded an earlier arrival of the detonation wave. Time-of-flight calculations indicated that the detonation wave eventually reached $\mathrm{CJ}$ velocity. The pressure records showed a rapid pressure rise. However, the transducers were unable to resolve the "von Neumann spike," the maximum pressure of the detonation front. The records show a rapid pressure drop associated with the Taylor rarefaction, as indicated in the figure. The Taylor rarefaction reduces the effective pressure pumping the driven gas to below the Chapman-Jouguet pressure at the trailing edge of the detonation front. There is a reduction in shock tube performance. The records also show peaks within the rarefaction region. These peaks are attributed to waves reflecting off the the diaphragm interface due to the practical limitation of having to place the igniter slightly away from the diaphragm position.

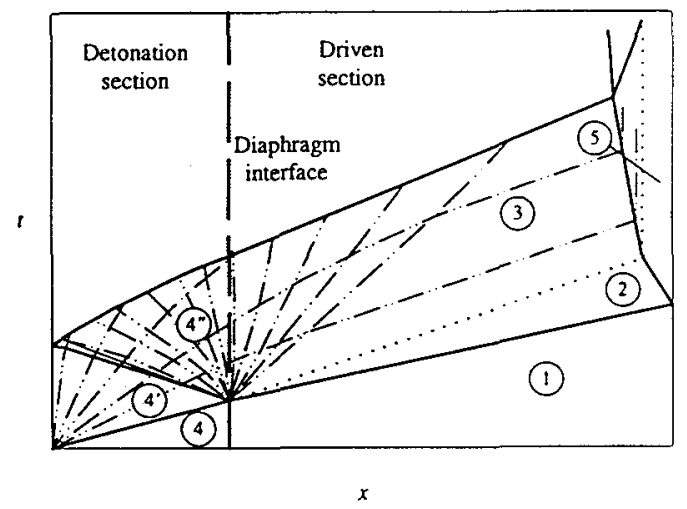

Figure 3: Downstream propagation mode.

In the upstream propagation mode, the ignition source is just upstream of the primary diaphragm, producing a detonation wave that propagates upstream. The detonation tube process is shown schematically in Fig. 5. The detonation wave propagates to the left into region 4. The pressure rise following the detonation wave is fairly constant but the momentum imparted to the driver gas by the detonation wave is directed upstream. This has adverse loading consequences on the shock tube.

An example of detonation tube pressure traces for the upstream propagation mode is shown in Fig. $6 .^{29}$ The

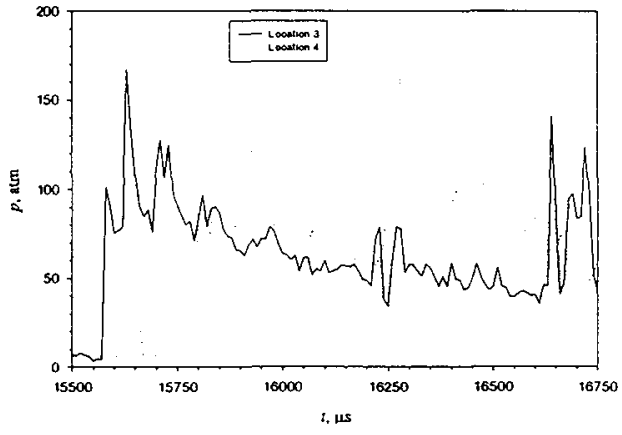

Figure 4: Pressure traces for downstream propagation mode (stoichiometric oxyhydrogen mixture at initial pressure of 6 atm, electric arc ignition).

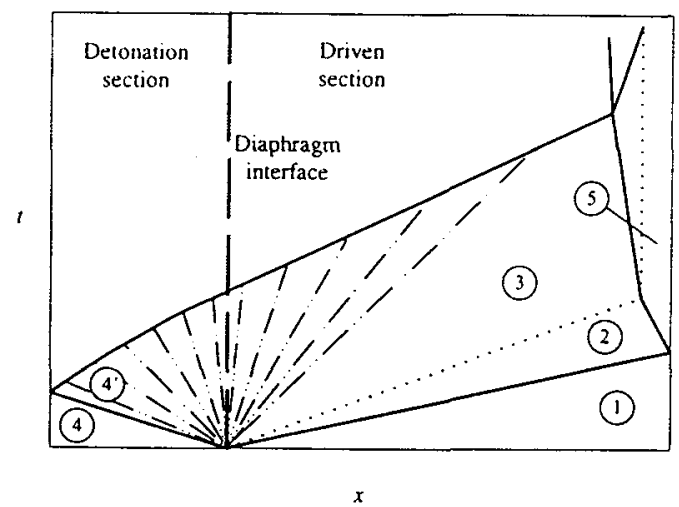

Figure 5: Upstream propagation mode. 


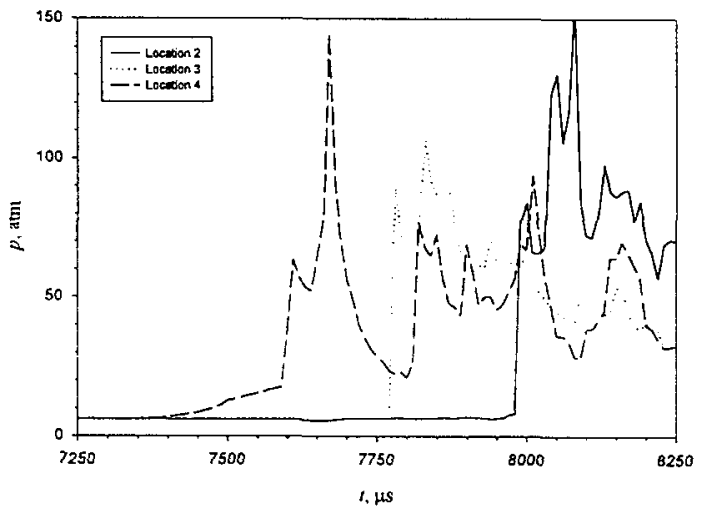

Figure 6: Pressure traces for upstream propagation mode (stoichiometric oxyhydrogen mixture at initial pressure of $6 \mathrm{~atm}$, electric arc ignition.

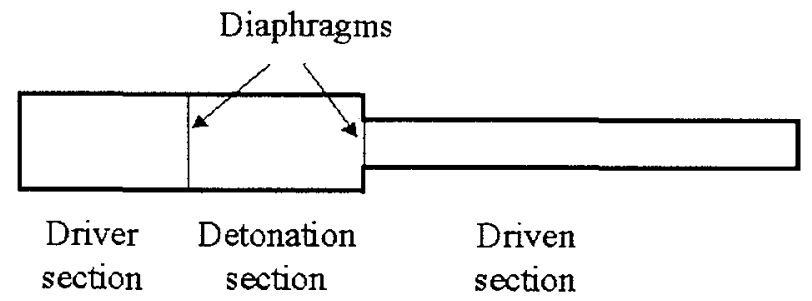

a. Schematic, with area reduction between detonation and driven sections.

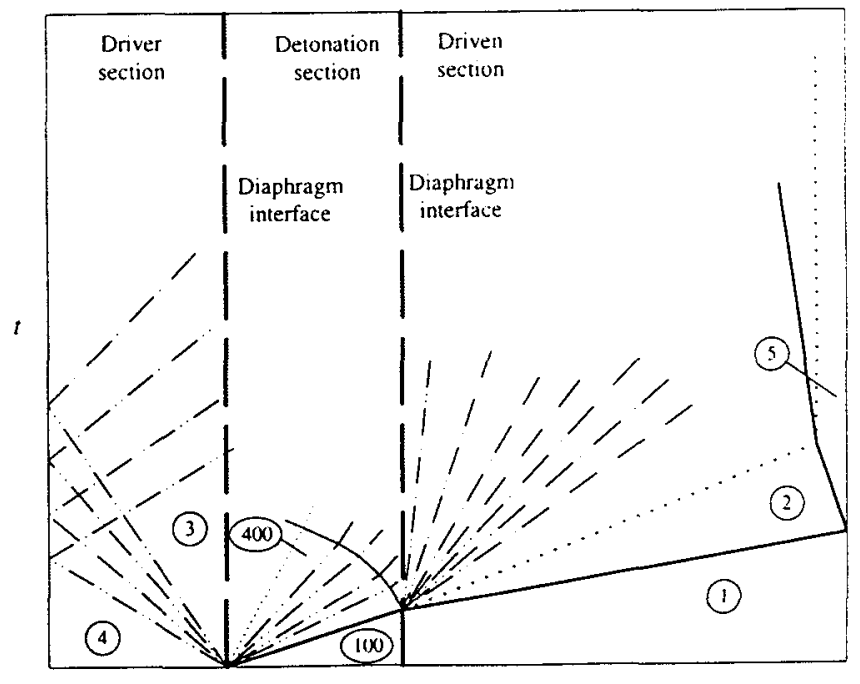

b. Wave diagram.

Figure 7: Downstream propagation mode using shock induced detonation. detonation tube was filled with a stoichiometric oxyhydrogen mixture at $6 \mathrm{~atm}$. Transducer (4) was closer to the igniter and thus recorded the arrival of the detonation wave before transducer (3). However, transducer (4) detected some precompression ahead of the detonation wave, indicating that the detonation wave did not reach the CJ velocity, a phenomenon also reported in Ref. 30. Transducer (3) as well as subsequent transducers upstream (not shown in Fig. 6 for clarity) did not detect any precompression. Time-of-flight calculations indicated that the detonation wave eventually reached CJ velocity. The pressure records indicated a rapid pressure rise after the precompression but the von Neumann spike was not resolved. The Taylor rarefaction and additional peaks in this region are also indicated in the figure.

For either propagation mode, further performance enhancement is possible by helium dilution to the oxyhydrogen mixture. Helium dilution raises the sonic speed in the driver gas, and also somewhat reduces the danger associated with premature detonation of the oxyhydro gen mixture. Performance calculations by $\mathrm{Yu}$, et al. ${ }^{18}$ indicate that the performance degradation caused by the slight lowering of the detonation temperature due to helium dilution is more than adequately offset by the increased sonic speed of the driver-tube gas.

Two of the institutions which have recently implemented detonation drivers make use of downstream propagation while the other two make use of upstream propagation (Table 1). Means of implementing these techniques to enable them to be used for test facilities are now elaborated separately in the following subsections.

\section{Downstream propagation}

Downstream propagation using arc ignition ${ }^{28}$ yielded shock speeds considerably lower than those predicted by a simple, one-dimensional model, thus yielding drastically lower pressure and temperature levels in state 2 of the driven gas. The primary reason was attributed to the Taylor rarefaction wave associated with the arcignition process for the downstream mode.

The decrease in pressure following the detonation front can be overcome by adding a driver tube ahead of the detonation tube, to initiate a shock-induced detonation. ${ }^{31}$ A detonation wave is generated in the combustible mixture by rupture of a diaphragm between the driver tube and the detonation tube. This method was apparently first used by Coates and Gaydon. ${ }^{15}$ These authors made use of the shock wave from a cold hydrogen driver to ignite a detonable mixture. Recently, shock-induced detonation was reintroduced by Bakos et al. ${ }^{25}$ and adopted by Stuessy et al. ${ }^{29}$

A schematic of the method, including an idealized wave diagram, is shown in Fig. 7 . In this figure, the detonation and driven sections are shown with different di- 


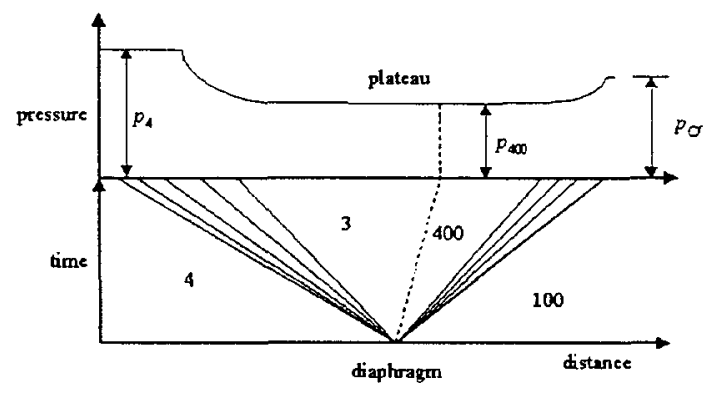

a. Under-driven detonation.

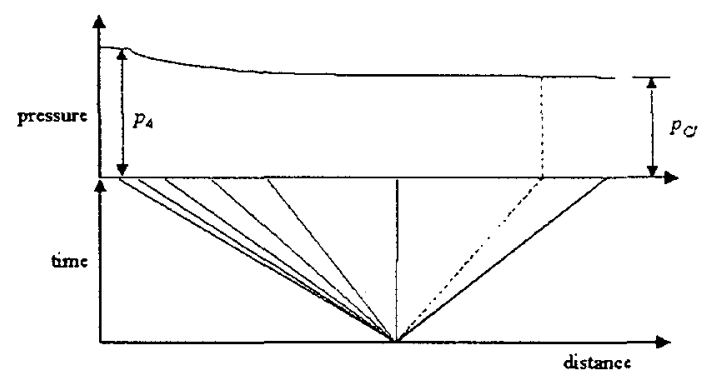

b. Perfectly-driven detonation.

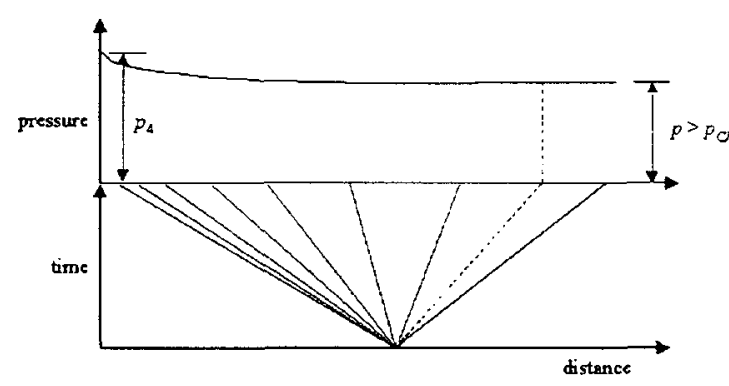

c. Over-driven detonation.

Figure 8: Different modes for shock-induced detonation.

ameters. This causes a slightly more complicated wave process. Labeling of the different regions in the wave diagram remains consistent with shock tube nomenclature. A high-pressure air or helium driver is placed upstream of the detonation tube. When the primary diaphragm is ruptured, a shock wave is driven into the detonation tube, labeled region 100 in Fig. $7 \mathrm{~b}$. This shock wave quickly initiates detonation. Unlike the closed-end operation (see Fig. 5), the driver tube serves to reduce or eliminate the Taylor rarefaction wave, thus resulting in a higher pressure available to drive the primary shock wave in the shock tube. In effect, the driver tube exhaust acts like a "gas piston" to sustain the pressure behind the incident detonation wave at a higher level than would occur if the detonation propagated away from a closed end-wall.

The strength of the primary shock driven into region
1 can be attenuated continuously by the Taylor rarefaction following the detonation wave. For example, the wave diagram in Fig. $7 \mathrm{~b}$ shows a weak detonation. This yields an "under-driven" condition. ${ }^{25}$ In this case, the extent of the Taylor rarefaction is just sufficient to balance the pressure of the expanding driver gas. The uniform region of detonation products behind the Taylor rarefaction and ahead of the driver gas interface is labeled 400 and appears as a pressure plateau $p_{400}$ in Fig. 8a. If the driver pressure is raised (that is. if $p_{4} / p_{100}$ is raised), a point will be reached such that the pressure of the expanding driver gas just balances that at the rear of the detonation wave $p_{C J}$, annikilating the Taylor rarefaction. In this "perfectly driven" mode, the full $\mathrm{CJ}$ pressure level can ideally be maintained behind the detonation wave, as shown in Fig. 8b. A further increase in $p_{4} / p_{100}$ causes the expanded driver gas pressure to be higher than the $\mathrm{CJ}$ wave pressure. This forces the detonation to travel faster than the C.J speed, resulting in an "over-driven" detonation. Taylor rarefaction also does not exist in this case.

Pressure traces of an under-driven and a nearly perfectly-driven detonation are shown in Figs. 9 and $10{ }^{29}$ The driver section was filled with air and helium respectively, with both gases at room temperature and at $210 \mathrm{~atm}$. Also, for both these cases, the detonation section contained a stoichiometric oxyhydrogen mixture at room temperature and at a pressure of $1.5 \mathrm{~atm}$. The driven tube was filled with air at room temperature and at a pressure of $0.14 \mathrm{~atm}$.

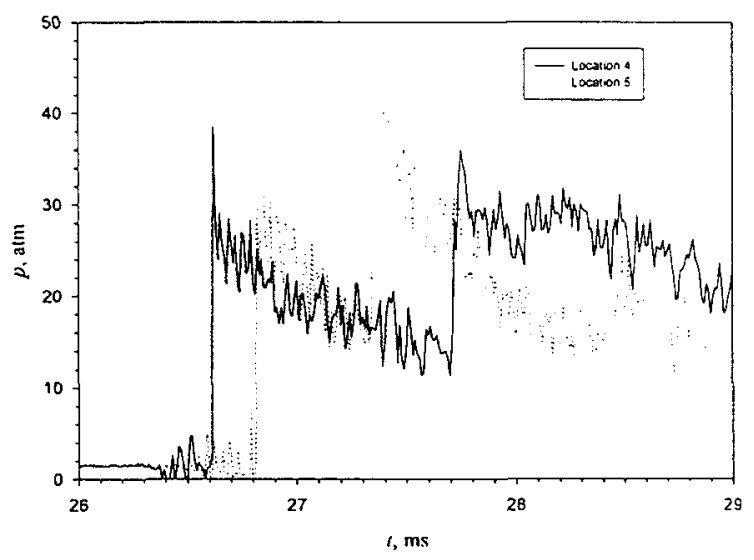

Figure 9: Example of an under-driven pressure trace.

In the under-driven mode shown in Fig. 9, the drop in pressure through the Taylor rarefaction wave is clearly indicated. The next increase in pressure recorded by the transducer is due to the arrival of the reflected detonation wave. In contrast, Fig. 10 shows a nearly perfectly-driven pressure trace with almost annihilation of the Taylor rarefaction. Furthermore, the pres- 
sure level achieved by the reflected detonation wave is much higher, with a corresponding increase in the driven-tube Mach number from 6.70 to 7.65. Driventube pressure traces for these two cases are shown in Figs. 11 and 12. Approximately $1 \mathrm{~ms}$ of adequately steady pressure downstream of the propagating shock was obtained for these two cases. Thus it appears that the shock-induced detonation mode offers substantial gains in performance by reducing or possibly eliminating the Taylor rarefaction wave.

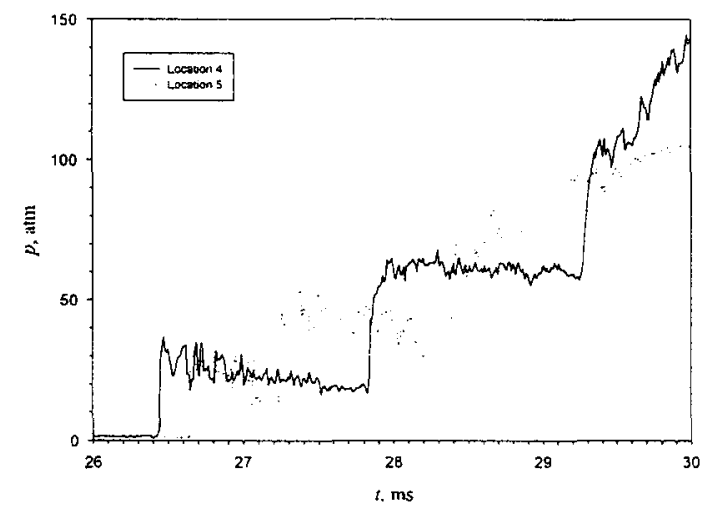

Figure 10: Example of a nearly perfectly-driven pressure trace.

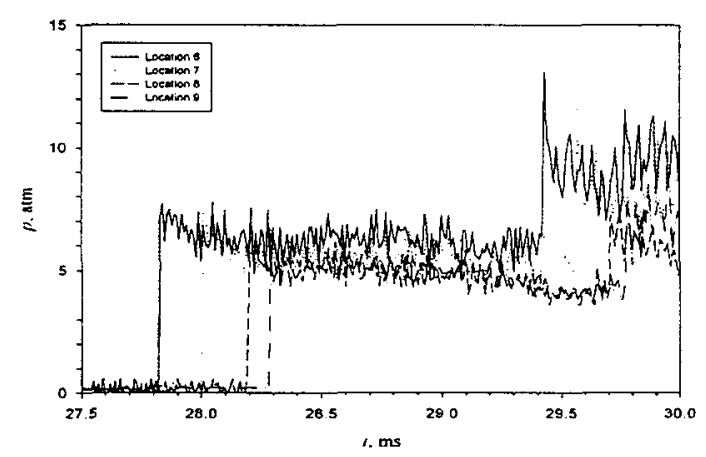

Figure 11: Pressure trace in driven tube corresponding to Fig. 9.

The downstream propagation mode of operation can be optimized by examining the performance of the driver and detonation sections. First, the pressure ratio $p_{4} / p_{100}$ must be sufficiently high to quickly initiate detonation. It has been suggested that detonable mixtures with diluent fractions up to 65 percent are sufficiently

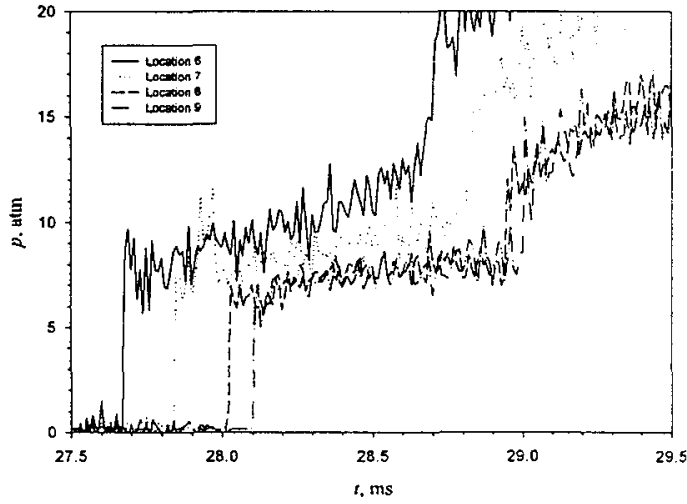

Figure 12: Pressure trace in driven tube corresponding to Fig. 10.

sensitive for achieving detonations at pressure ratios as low as $20 .^{27}$

The choice of the driver-to-detonation tube fill ratio $p_{4} / p_{100}$ and the composition of the detonable mixture can be optimized to yield the highest-post shock pressures in the shock tube and maximum steady flow time. Unlike a conventional shock tube driver, the detonation products in this driver system propagate downstream. Consequently, the strength of the driven shock wave depends on the propagation velocity in addition to the sound speed and pressure in region 400. These three parameters depend on the initial tube fill ratio and the composition of the driver and detonable gases.

To simplify the optimization, an "effective" pressure $p_{e}$ and sound speed $a_{e}$ can be defined for the propagating detonation products. The effective values are those of a conventional static driver that would deliver the same shock strength in a given shock tube. They are related to the actual values in region 400 by

$$
\begin{aligned}
& p_{e}=p_{400}\left(1+\frac{\gamma-1}{2} M_{400}\right)^{2 \gamma /(\gamma-1)} \\
& a_{e}=a_{400}\left(1+\frac{\gamma-1}{2} M_{400}\right) .
\end{aligned}
$$

The above equations show that the downstream propagation velocity augments the pressure and sound speed relative to the static values.

For reflected shock tunnel operation, the optimization proceeds by choosing the effective sound speed that will tailor the driver-test gas interface in order to yield maximum test time. Then the effective pressure is maximized relative to the peak pressure that occurs in the driver during the operating cycle. Naturally, it is this pressure which must be maintained within the design pressure limit of the driver vessel. Referring to Fig. 8, depending on the initial fill pressure ratio, the peak 
pressure will be either the initial driver fill pressure, or the pressure immediately following the $\mathrm{CJ}$ wave.

Figure 13 is an example from the optimization process for a particular stoichiometric oxyhydrogen mixture with 30 percent argon diluent. The driver gas is helium. The effective pressure of the detonation products, normalized by either the driver pressure or the CJ pressure (whichever is higher), is shown as a function of the fill pressure ratio. At the lowest fill pressure ratio, the driver does not push on the detonation products and provides no forward velocity. This yields an effective pressure that is less than 40 percent of the peak pressure behind the $\mathrm{CJ}$ wave. At the highest fill pressure ratio shown, the driver pressure is sufficient to maintain the pressure behind the $\mathrm{CJ}$ wave constant; however, the effective pressure achieved is only 35 percent of the fill pressure. In between these extremes, at a fill pressure ratio of approximately 20 , the normalized effective pressure reaches a maximum of 75 percent. Because the pressure ratio generated by the CJ wave for this mixture is also approximately 20 , optimum performance occurs when the drive fill pressure and the post-CJ pressures are equal.

Figure 13 shows that the effective sound speed of the detonation products changes slowly with the fill pressure ratio for a given composition. This effective sound speed needs to be considered for tailored shock tunnel operation. Of note is that the sound speed of the detonation products is greater than that of the ambient temperature helium driver gas, indicating that the detonation technique allows tailored operation at higher enthalpy than does the helium driver alone. This is consistent with the aims of high performance driver techniques as elaborated earlier.

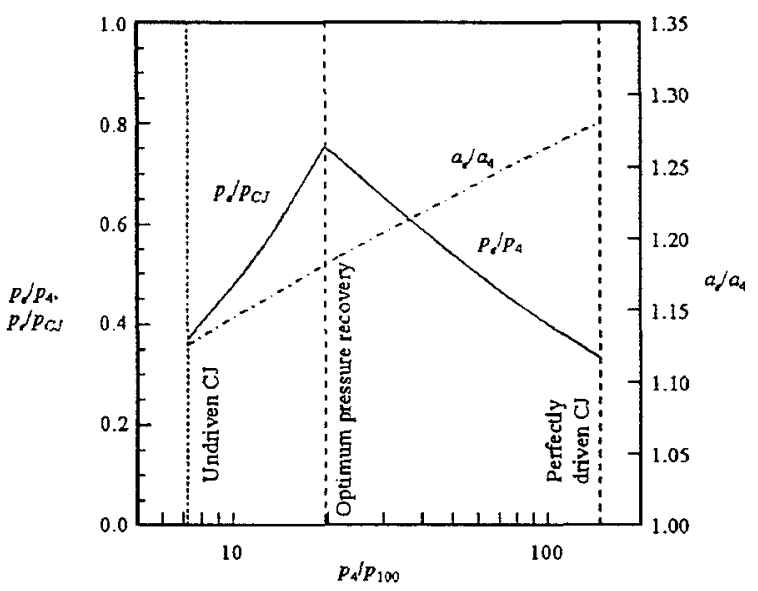

Figure 13: Dependence of normalized $p_{e}$ and $a_{e}$ on the light-gas driver to detonation fill pressure $\left(4.67 \mathrm{H}_{2}+\right.$ $\left.2.33 \mathrm{O}_{2}+3 \mathrm{Ar}\right)$.

\section{Upstream propagation}

As highlighted previously, the upstream propagation

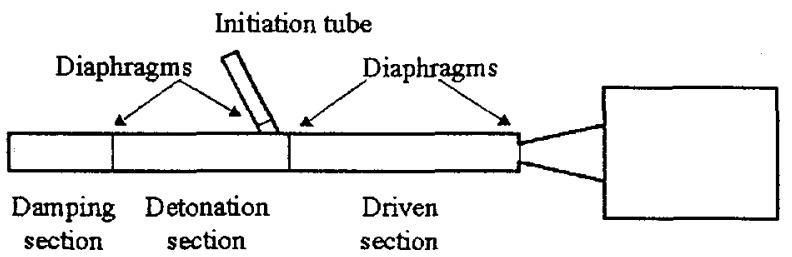

a. Schematic of detonation-driven shock tube in upstream propagation mode. ${ }^{13}$

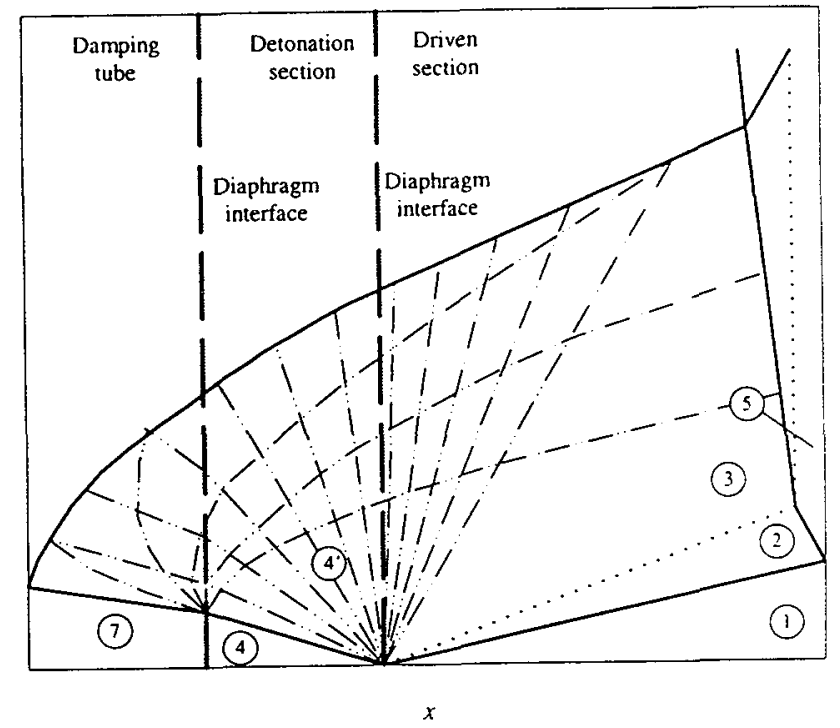

b. Wave diagram.

Figure 14: Shock tube with detonation driver, and additional initiation and damping tubes.

mode provides a fairly steady supply pressure for driving the shock wave into the driven tube. However, shock reflection at the closed end of the driver tube produces a structural problem. The reflected wave pressure may exceed 200 times the initial driver pressure. ${ }^{32}$ For initial driver pressures of $10 \mathrm{MPa}$ or more, the high value of the reflected wave pressure may destroy the facility. This can be overcome by adding a "damping tube" to the upstream end of the driver tube. ${ }^{13}$ A schematic of the test facility and an accompanying, ideal wave diagram are shown in Fig. 14. The damping tube is separated from the driver tube by a light diaphragm. Figure 14b indicates that an upstream propagating detonation wave would break this diaphragm and continue to propagate into the damping tube. The high pressure that would otherwise occur due to shock reflection is well attenuated. The damping tube absorbs the shock loading and helps to reduce the structural load. Moreover, the damping tube increases the test time if the tube is used to supply a shock tunnel, as is evident from the wave diagram of Fig. 14b.

The damping pressure and damping gas can be optimized to minimize the endwall loading. The wave structure in the damping tube depends on the ratio of the 
CJ pressure to the initial pressure in the damping tube. The predicted peak endwall pressure is shown in Fig. 15 and the value averaged over $30 \mathrm{~ms}$ is shown in Fig. 16. The figures show that air is suitable as the damping medium. Calculations indicate that $p_{7}$ needs to be no less than $p_{C J} \times 10^{-4}$ or, equivalently, $0.002 p_{4}$. Tailoring to maximize the test time, unlike conventional shock tubes which is achieved by a unique value of $p_{4} / p_{1}$, is achieved by adjusting the oxyhydrogen ratio.

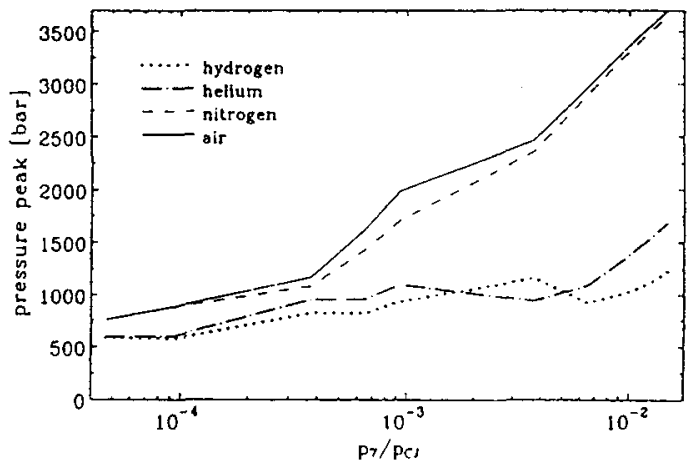

Figure 15: Peak endwall pressure of the damping tube as a function of $p_{C J} / p_{7}$.

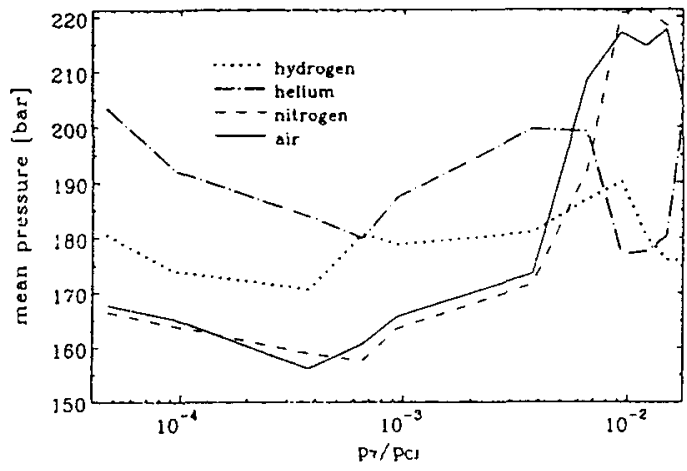

Figure 16: Mean endwall pressure of the damping tube as a function of $p_{C J} / p_{7}$.

Finally, Yu et al. found that helium addition in general does not improve the operation of the detonation tube. They used a rich mixture of hydrogen and oxygen. This mixture is ignited by the detonation of a combustible gas in an initiation tube which breaks the diaphragm and starts a detonation wave moving leftwards. Normal shock tube behavior occurs but with CJ conditions behind the detonation wave until the reflected detonation wave interacts with the reflected shock wave from the end of the driven section. The reflection of the detonation wave can be influenced by the choice of the gas and the pressure in the damping tube.

\section{Ignition}

There are two methods of ignition, 33 a slow or "self" initiation by a low energy source and a fast or "direct" initiation by an energetic source. In self initiation, a deflagration front transitions to a detonation. The underlying mechanisms for deflagration-to-detonation (DDT) remain unclear and the DDT length can vary substantially depending on how well the gases are mixed and other factors. Hence, this process is not considered viable for facility development because it may not yield reproducible conditions.

Development of a viable technique for detonation drivers centers on direct initiation where the detonation forms almost instantaneously at the immediate vicinity of the igniter. The ignition process is crucial to the success of detonation drivers. In general, the ignition energy must exceed a certain threshold. This critical amount of energy for direct initiation depends on the mixture ratio for given pressure and temperature, and igniter. Its minimum occurs at stoichiometric ratios. ${ }^{34}$ However, $\mathrm{Yu}$ and $\mathrm{Zhao}{ }^{21}$ suggested that a gain in shock Mach number can be achieved with a hydrogen-rich mixture up to a $\mathrm{H}_{2} / \mathrm{O}_{2}$ ratio of 5 at high initial pressure $P_{41} \gtrsim 100$. Obviously, an energetic igniter is necessary in such a situation.

Methods used for direct initiation include the use of an exploding wire, electric arc ignition (sparks), explosives, lasers, and shock-induced detonation. Lee ${ }^{17}$ exploded a $75 \mu \mathrm{m}$ copper wire near the face of a diaphragm to initiate detonation in an equimolar acetylene-oxygen mixture at atmospheric pressure. A shock Mach number up to about 8 was obtained at a pressure ratio $P_{51}$ of 50 . Higher shock Mach numbers were thought possible by increasing the driver pressure. $\mathrm{Yu}$ and $\mathrm{Zhao}^{2 \mathrm{l}}$ found that sparks and exploding wires yielded weak detonations. Instead, they directly initiated detonations in oxyhydrogen mixtures using a 20 mg tetryl pellet. However, there was significant contamination and erosion of the facility. Stuessy et al. ${ }^{28}$ used an energetic arc source capable of delivering 20-25 $\mathrm{J}$ in $60 \mu \mathrm{s}$.

In shock-induced detonation, the shock is generated either by using an auxiliary driver filled with high pressure gas such as air, nitrogen, helium, ${ }^{26,29}$ or hydrogen,${ }^{35}$ or it is generated by a detonation using an "initiation tube," or pre-igniter. 13,21 Shock-induced detonation appears to be the most attractive for the downstream propagation mode, with the potential of minimizing the adverse Taylor rarefaction.

\section{Comparison of High Performance Facilities}

The fundamental difference between the upstream and downstream modes is the direction of the detonationinduced velocity relative to the detonation wave propagation direction. To assess the effect of this difference on performance, the effective static driver concept can be used. For the upstream mode, the effective driver 
state is related to the $\mathrm{CJ}$ state by

$$
\begin{aligned}
& p_{e}=p_{C J}\left(1-\frac{\gamma-1}{2} M_{C J}\right)^{2 \gamma /(\gamma-1)} \\
& a_{e}=a_{C J}\left(1-\frac{\gamma-1}{2} M_{C J}\right)
\end{aligned}
$$

Performance of the two cycles, with the same initial conditions as in Fig. 13, is compared in Fig. 17. For the upstream mode, the peak cycle pressure is the CJ pressure while for the downstream mode, the cycle is assumed optimized as shown in Fig. 13 such that the $C J$ pressure and the light-gas driver pressure are equal and represent the peak cycle pressure. The downstream mode delivers approximately double the pressure performance over the effective sound speed range of interest in comparison to the upstream mode. Note that the temperatures are greater than room-temperature helium.

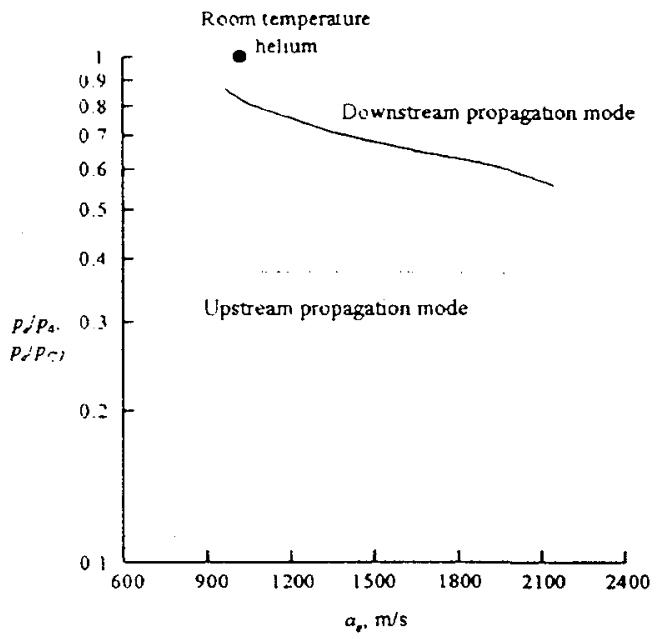

Figure 17: Pressure recovery of upstream and downstream modes.

Table 1 summarizes the detonation-driven facilities known to the authors. The UTA facility is a shock tube and is currently used for high-pressure plasma and combustion research. ${ }^{29}$ The other facilities are devoted to aerodynamics testing. Table 2 shows that, amongst the different techniques for generating high-enthalpy flows, detonation-driven facilities occupy an important niche. Detonation-driven facilities produce enthalpies below that of free piston tunnels but above that of gun tunnels. The enthalpies, when expressed in terms of the binary scaling parameter, are in the range of the reentry corridor. ${ }^{23}$ Even though the performance is below that of the free piston tunnel, detonation-driven facilities have a few attractive features. First, they are relatively easy to operate, without the problems associated with a heavy piston, such as piston erosion and rebound. Also, there is no need for thick diaphragms to contain high pressure gas. However, the safe han- dling of large amounts of hydrogen must be carefully considered.

\section{Outlook and Conclusions}

Recent developments in detonation drivers have indicated that high performance can be obtained for meaningful hypervelocity testing. There are two preferred ways of implementing detonation techniques, namely: a downstream and an upstream detonation mode, depending on the direction of the detonation wave. The downstream propagation mode makes use of shockinduced detonation and can be operated as underdriven, perfectly driven or overdriven, this classification being governed by the subsequent, wave structure Ideally, the Taylor rarefaction should be annihilated by the high-pressure driver. In the upstream propagation mode, the Taylor rarefaction problem does not truly. exist. However, structural problems require the use of a damping tube. The wave processes in the upstream propagation mode also results in a potentially longer run time than the downstream mode. Theoretical considerations indicate that a higher performance can be obtained by the downstream propagation mode

The operation of detonation-driven facilities is thought to be simpler than that of free piston tunnels. However, the enthalpies that are obtained are somewhat lower. Nevertheless, detonation-driven facilities can make a useful contribution to the study of various gasdynamics problems. There remains the potential for developing new ways of operating detonation-driven facilities with better understatuding of detonations. 36.37 Finally, the possibility of hybrid drivers. combining pistons and detonations may open up a new class of highperformance facilities.

\section{Acknowledgements}

The authors would like to thank Professor Hans Grönig of the University of Technology, Aachen, Germany and Professor Hongru Yu of the Institute of Mechanics, Chinese Academy of Sciences, Beijing, China, for generously sharing their papers and results with us.

\section{References}

'Trimmer, L. L., Cary, A. M., Jr. and Voisinet, R. L.. "The Optimum Hypersonic Wind Tunnel," ALAA Paper $86-$ 0739,1986

${ }^{2}$ Morgan, R. G., "A Review of the Use of Expansion Tubes for Creating Superorbital Flows," AlAA Paper 97-0279. 1997.

${ }^{3}$ Chinitz, W., Erdos, J. I., Rizkalla, O., Anderson, G. Y. and Bushnell, D. M., "Facility Opportunities and Associated Stream Chemistry Considerations for Hypersonic AirBreathing Propulsion," AIAA Journal of Propulsion and Power, Vol. 10, No. 1, 1994, pp. 6-17.

${ }^{4}$ Pratt, D. T., Humphrey, J. W. and Glenn, D. E., "Morphology of Standing Oblique Detonation Waves," AlAA 
Journal of Propulsion and Power, Vol. 7, No. 5, 1991, pp. 837-845.

${ }^{5}$ Miles, R. B., Brown, G. L., Lempert, W. R., Yetter, R., Williams, G. J., Jr., Bogdonoff, S. M., Natelson, D. and Guest, J. R., "Radiatively Driven Hypersonic Wind Tunnel," AIAA Journal, Vol. 33, No. 8, 1995, pp. 14631470.

${ }^{6}$ Nelson, G. L. and Simmons, G. A., "Augmentation of Hypersonic Propulsion Test Facilities Using MHD," AIAA Paper 95-1937, 1995.

${ }^{7}$ Warren, W. R. and Harris, C. J., "A Critique of High Performance Shock Tube Driving Techniques," in Shock Tubes. Proceedings of the 7th International Shock Tube Symposium, edited by I. I. Glass, University of Toronto Press, 1970, pp. $143-176$

${ }^{\circ}$ Gai, S. L., "Free Piston Shock Tunnels: Developments and Capabilities," Progress in Aerospace Sciences, Vol. 29, 1992, pp. 1-41.

${ }^{9}$ Cox, R. N. and Winter, D. F. T., "The Light Gas Gun at ARDE, Fort Halstead, Kent," AGARD Report 139, 1957.

${ }^{10}$ Bakos, R. J. and Erdos, J. I., "Options for Enhancement of the Performance of Shock-Expansion Tubes and Tunnels," AIAA Paper 95-0799, 1995.

"Eitelberg, G., McIntyre, T. J., Beck, W. H. and Lacey, J., "The High Enthalpy Shock Tunnel in Göttingen," AIAA Paper 92-3942, 1992.

${ }^{12}$ Bogdanoff, D. W., Zambrana, H. A., Cavolowsky, J. A., Newfield, M. E., Cornelison, C. J. and Miller, R. J., "Reactivation and Upgrade of the NASA Ames 16 Inch Shock Tunnel," AIAA Paper 92-0327, 1992.

${ }^{13} \mathrm{Yu}$, H. R., Esser, B., Lenartz, M. and Grönig, H., "Gaseous Detonation Driver for a Shock Tunnel." Shock Waves, Vol. 2, 1992, pp. 245-254.

${ }^{14}$ Bird, G. A., "A Note on Combustion Driven Shock Tubes," in "Hypersonic Facilities in the Aerodynamics Department, Royal Aircraft Establishment," edited by P. A. Hufton, AGARD Report 146, 1957.

${ }^{15}$ Coates, P. B. and Gaydon, A. G., "A Simple Shock Tube with Detonating Driver Gas," Proceedings of the Royal Society, Vol. A283, 1965, pp. 18-32.

${ }^{16}$ Balcarzak, M. Journal of and Johnson, M. R., "The Gaseous-Detonation Driver and Its Application to Shock Tube Simulation Techniques," in Proceedings of the 5th International Shock Tube Symposium, edited by Z.I. Slawsky. J.F. Moulton and W.S. Filler, 1966, U.S. Naval Ordnance Laboratory, White Oak, Maryland, pp. 1111-1128.

${ }^{17}$ Lee, B. H. K., "Detonation-Driven Shocks in a Shock Tube," AIAA Journal, Vol. 5, No. 4, 1967, pp. 791-792.

${ }^{18} \mathrm{Yu}, \mathrm{H} .-\mathrm{R}$, "Recent Developments in Shock Tube Applications," in Proceedings of the National Symposium on Shock Wave Phenomena, edited by K. Takayama, September 28-30, 1989, Sendai, Japan, pp. 1-9.

${ }^{19} \mathrm{Yu}, \mathrm{H} .-\mathrm{R}$., "Experimental Study of Oxyhydrogen Detonation Driver for a Shock Tunnel," International Shock Wave Symposium, March 16-18, 1995, Yokohama, Japan.

${ }^{20} \mathrm{Yu}, \mathrm{H} .-\mathrm{R}$., Zhao, W. and Yuan, S., "Performance of Shock Tunnel with $\mathrm{H}_{2}-\mathrm{O}_{2}$ Detonation Driver," Aerodynamic Experiment and Measurement \& Control, Vol. 7, 1994, pp. 38-42 (in Chinese).

${ }^{21} \mathrm{Yu}, \mathrm{H} .-\mathrm{R}$. and Zhao, W., "The Use of Oxyhydrogen Detonation Driver for Generation of High Enthalpy Flow," 20th International Symposium on Rarefied Gas Dynamics, August 19-23, 1996.
${ }^{22} \mathrm{Yu}$, H.-R., Lin, J. M., Zhao, W., Li, Z. F. and $\mathrm{Gu}$ : J. H., "A New Shock Tunnel with Oxyhydrogen Detonation Driver," Paper 6070, 21st International Symposium on Shock Waves, July 20-25, 1997, Great Keppel Island, Australia.

${ }^{23}$ Lenartz, M., Wang, B. and Grönig, H., "Development of a Detonation Driver for a Shock Tunnel," 20th International Symposium on Shock Waves, Pasadena, California, USA. 1995.

${ }^{24}$ Engers, R. J., Calleja, J. F. and Bakos, R. J., "A Der. onation Driven Injectant Heater for Pulse Facility Testing Applications," AIAA Paper 95-3153, 1995.

${ }^{25}$ Bakos, R. J., Castrogiovanni, A., Calleja, J. F.. Nucci. L. and Erdos, J. I., "Expansion of the Scramjet Ground Test Envelope of the HYPULSE Facility," AIAA Paper 96-4506. 1996.

${ }^{26}$ Erdos, J. I., Bakos, R. J. and Rogers, R. J., "Dual Mlsd": Shock-Expansion/Reflected-Shock Tunnel," AIAA Paper 97-0560, 1997.

${ }^{27}$ Bakos, R. J. and Erdos, J. I., "Optimizing Pressure Recovery in a Detonation Driven Reflected Shock Tunnel." $P_{i}$ per 5999, 21st International Symposium on Shock Wiaves. July 20-25, 1997, Great Keppel [sland, Australia.

${ }^{28}$ Stuessy, W. S., Liu, H.-C., Lu, F. K. and Wilson. D. R. "Initial Operation of a High-Pressure Detonation-Driven Shock Tube Facility," AlAA Paper 97-0665, 1997

${ }^{29}$ Stuessy, W. S., Lu, F. K. and Wilson, D. R., "Shock $I_{\mathrm{I}}$ duced Detonation Wave Driver for Enhanching Shock Tube: Performance," AIAA Paper 98-0549, 1998.

${ }^{30}$ Helman, D., Shreeve, R. P. and Eidelman, S. "Detoriation Pulse Engine," AIAA Paper 86-1683, 1986.

${ }^{31}$ Edwards, D. H., Thomas, G. O. and Williams. T. L. "Initiation of Detonation by Unsteady Planar Incident Shock Waves," Combustion and Flame, Vol. 43. $19 \% 1$. pp. 187-198.

${ }^{32}$ Edwards, D. H., Williams, G. T. and Breeze J. C. "Pressure and Velocity Measurements on Detonation Wates in Hydrogen-Oxygen Mixture," Journal of Fluid Mecharics. Vol. 6, Part 4, 1959, pp. 497-517.

${ }^{33}$ Lee, J. H. S., "Dynamic Parameters of Gaseous Deronations," Annual Review of Fluid Mechanics. Vol. 16. 19ミ4 pp. 311-336.

${ }^{34}$ Nettleton, M. A., Gaseous Detonations, Chapman and Hall, London, 1987.

${ }^{35}$ Gier, H. L. and Jones, T. G., "An Investigation of a Double Diaphragm Shock Tube with a Detonable Buffer Gas." in Shock Tubes. Proceedings of the 7th International Shock Tube Symposium, June 23-25, 1969, edited by I. I. Glass. University of Toronto Press, 1970, pp. 272-290.

${ }^{36}$ Eckett, C. A., Quirk, J. and Shephard, J. E., "A New Model for Direct Initiation of Gaseous Detonations," Paper 2100, 21st International Symposium on Shock Waves. July" 20-25, 1997, Great Keppel Island, Australia.

${ }^{37}$ Gelfand, B. E., Popov, O. E., Medvedev, S. P., Khorrik. S. V., Kusharin, A. Y. and Agafonov, G. L., "Self-Ignition of Hydrogen-Oxygen Mixtures at High Pressure," Paper 2400. 21st International Symposium on Shock Waves, July 20-25. 1997, Great Keppel Island, Australia.

${ }^{38}$ Lenartz, M., "Entwicklung eines Detonationstreibers für den Stoßwellenkanal," Ph.D. dissertation, University of Technology, Aachen, Germány, 1996. 
Table 1: Summary of detonation drivers.

\begin{tabular}{|c|c|c|c|}
\hline Facility & Detonation driver & Driven tube & $\begin{array}{l}\text { Approx. max. } \\
\text { test conditions }\end{array}$ \\
\hline $\begin{array}{c}\text { University of Texas } \\
\text { at Arlington, USA } \\
\text { (up/downstream propagation, } \\
\text { arc initiation) }\end{array}$ & 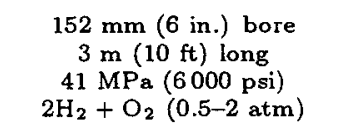 & $\begin{array}{c}41.2 \mathrm{~mm}(1.62 \mathrm{in} .) \text { bore } \\
9 \mathrm{~m}(30 \mathrm{ft}) \text { long } \\
19 \mathrm{MPa}(2800 \mathrm{psi})\end{array}$ & $\begin{array}{l}28 \text { atm } \\
2450 \mathrm{~K}\end{array}$ \\
\hline $\begin{array}{c}\text { University of Texas } \\
\text { at Arlington, USA } \\
\text { (downstream propagation, } \\
\text { shock initiation) }\end{array}$ & $\begin{array}{c}152 \mathrm{~mm}(6 \mathrm{in} .) \text { bore } \\
3 \mathrm{~m}(10 \mathrm{ft}) \text { long } \\
41 \mathrm{MPa}(6000 \mathrm{psi}) \\
2 \mathrm{H}_{2}+\mathrm{O}_{2}(0.5-2 \mathrm{~atm})\end{array}$ & $\begin{array}{c}41.2 \mathrm{~mm}(1.62 \mathrm{in} .) \text { bore } \\
9 \mathrm{~m}(30 \mathrm{ft}) \mathrm{long} \\
19 \mathrm{MPa}(2800 \mathrm{psi})\end{array}$ & $\begin{array}{l}40.5 \mathrm{MPa} \\
7000 \mathrm{~K}\end{array}$ \\
\hline $\begin{array}{c}\text { GASL, Ronkonkoma, } \\
\text { New York, USA } \\
\text { (downstream propagation, } \\
\text { shock initiation) }\end{array}$ & $\begin{array}{c}150 \mathrm{~mm}(6 \mathrm{in} .) \text { bore } \\
\text { up to } 12 \mathrm{~m}(39 \mathrm{ft}) \text { long } \\
140 \mathrm{MPa}(20300 \mathrm{psi}) \\
2 \mathrm{H}_{2}+\mathrm{O}_{2}+\mathrm{Ar}(1-17 \mathrm{~atm})\end{array}$ & $\begin{array}{l}150 \mathrm{~mm}(6 \mathrm{in} .) \text { bore } \\
\text { up to } 21 \mathrm{~m}(69 \mathrm{ft}) \text { long } \\
53 \mathrm{MPa}(7700 \mathrm{psi})\end{array}$ & $\begin{array}{c}T_{0}=5000 \mathrm{~K} \\
h_{0}=7 \mathrm{MJ} / \mathrm{kg}\end{array}$ \\
\hline $\begin{array}{c}\text { University of Technology, } \\
\text { Aachen, Germany } 23 \\
\text { (upstream propagation, } \\
\text { shock initiation } \\
\text { with damping tube) }\end{array}$ & $\begin{array}{c}140 \mathrm{~mm}(5.5 \mathrm{in} .) \text { bore } \\
6.16 \mathrm{~m}(20.2 \mathrm{ft}) \text { long } \\
2 \mathrm{H}_{2}+\mathrm{O}_{2}(15 \mathrm{~atm})\end{array}$ & $\begin{array}{c}140 \mathrm{~mm}(5.5 \mathrm{in} .) \text { bore } \\
6.2 \mathrm{~m}(20.3 \mathrm{ft}) \text { long }\end{array}$ & $\begin{array}{c}h_{o}=7.8 \mathrm{MJ} / \mathrm{kg} \\
M_{s}=9.6 \\
u_{\infty}=4.8 \mathrm{~km} / \mathrm{s}\end{array}$ \\
\hline $\begin{array}{c}\text { Institute of Mechanics, } \\
\text { Chinese Academy of Sciences, } \\
\text { Belfing, China } 21 \\
\text { (upstream propagation, } \\
\text { shock initiation } \\
\text { with damping tube) }\end{array}$ & $\begin{array}{l}100 \mathrm{~mm}(4 \mathrm{in} .) \text { bore } \\
5.6 \mathrm{~m}(18.4 \mathrm{ft}) \text { long } \\
3 \mathrm{H}_{2}+\mathrm{O}_{2}(10 \mathrm{~atm})\end{array}$ & 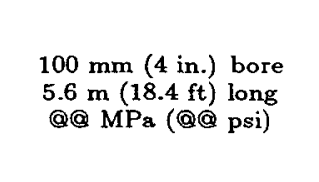 & $M_{s}=10.7$ \\
\hline
\end{tabular}

Notes:

1. Dimensions and fill conditions are representative. These may have changed.

2. GASL: light gas driver $=2.4 \mathrm{~m}$ long; pressure up to $140 \mathrm{MPa}$.

3. TU Aachen: damping tube $=140 \mathrm{~mm}$ dia., $6.1 \mathrm{~m}$ long; initiation tube $=30 \mathrm{~mm}$ dia., $900 \mathrm{~mm}$ long. 
Table 2: Comparison of maximum performance of different facilities (adapted from Ref. 38).

\begin{tabular}{|c|c|c|c|}
\hline Facility & $\begin{array}{c}\text { Stagnation } \\
\text { pressure, MPa }\end{array}$ & $\begin{array}{c}\text { Stagnation } \\
\text { temperature, } \mathrm{K}\end{array}$ & $\begin{array}{c}\text { Stagnation } \\
\text { enthalpy, } \mathrm{MJ} / \mathrm{kg}\end{array}$ \\
\hline \multicolumn{4}{|l|}{ Shock tunnels } \\
\hline $\begin{array}{c}\text { TH2, University of } \\
\text { Technology, Aachen, Germany }\end{array}$ & 63 & 4700 & 6.8 \\
\hline $\begin{array}{c}\text { LENS, Calspan, } \\
\text { Buffalo, New York, USA }\end{array}$ & 130 & 8000 & 14.4 \\
\hline $\begin{array}{l}\text { Rennselaer Polytechnic, } \\
\text { Troy, New York, USA }\end{array}$ & 5.8 & 4100 & 6.3 \\
\hline \multicolumn{4}{|l|}{ Free piston tunnels } \\
\hline $\begin{array}{l}\text { HEG, Göttingen, } \\
\text { Germany }\end{array}$ & 91 & 9730 & 22.3 \\
\hline $\begin{array}{c}\text { TCM2, Marseille, } \\
\text { France }\end{array}$ & 123 & 7000 & 25 \\
\hline $\begin{array}{l}\text { T4, Univ. of Queensland, } \\
\text { Brisbane, Australia }\end{array}$ & 200 & 8600 & 15.8 \\
\hline $\begin{array}{l}\text { T5, Caltech, Pasadena, } \\
\text { California, USA }\end{array}$ & 62 & 9050 & 22 \\
\hline \multicolumn{4}{|l|}{ Gun tunnels } \\
\hline $\begin{array}{l}\text { Longshot, VKI, } \\
\text { Brussels, Belgium }\end{array}$ & 400 & 2500 & 3 \\
\hline $\begin{array}{l}\text { C2, LBRA, Vernon, } \\
\text { France }\end{array}$ & 35 & 2400 & 2.8 \\
\hline $\begin{array}{l}\text { UTIAS, Toronto, } \\
\text { Canada }\end{array}$ & 36 & 2100 & 2.4 \\
\hline $\begin{array}{l}\text { No. 2, Imperial College, } \\
\text { London, UK }\end{array}$ & 55 & 1070 & 1.1 \\
\hline $\begin{array}{l}\text { University of } \\
\text { Southampton, UK }\end{array}$ & 60 & 1100 & 1.2 \\
\hline \multicolumn{4}{|l|}{ Hot shot tunnel } \\
\hline $\begin{array}{l}\text { F4, Le Fauga, } \\
\text { France }\end{array}$ & 200 & 5500 & 16 \\
\hline \multicolumn{4}{|l|}{$\begin{array}{l}\text { Detonation driven } \\
\text { tunnel/tube }\end{array}$} \\
\hline $\begin{array}{l}\text { University of Texas } \\
\text { at Arlington, USA }\end{array}$ & 40.5 & 7000 & 12.5 \\
\hline $\begin{array}{l}\text { GASL, Ronkonkoma, } \\
\text { New York, USA }\end{array}$ & 34 & 5000 & 7 \\
\hline $\begin{array}{c}\text { TH2, University of } \\
\text { Technology, Aachen, Germany }\end{array}$ & 28 & 7520 & - \\
\hline
\end{tabular}

